\title{
Expression profile of oxidative and antioxidative stress enzymes based on ESTs approach of citrus
}

\author{
Luis Antonio Peroni ${ }^{1}$, Renato Rodrigues Ferreira ${ }^{2}$, Antonio Figueira ${ }^{2}$, Marcos Antonio Machado ${ }^{3}$ \\ and Dagmar Ruth Stach-Machado ${ }^{1}$ \\ ${ }^{I}$ Departamento de Microbiologia e Imunologia, Universidade Estadual de Campinas, Campinas, SP, Brazil. \\ ${ }^{2}$ Laboratório de Melhoramento de Plantas, Centro de Energia Nuclear na Agricultura, \\ Universidade de São Paulo, Piracicaba, SP, Brazil. \\ ${ }^{3}$ Centro APTA Citros Sylvio Moreira, Instituto Agronômico de Campinas, Cordeirópolis, SP, Brazil.
}

\begin{abstract}
Plants not only evolve but also reduce oxygen in photosynthesis. An inevitable consequence of this normal process is the production of reactive oxygen species (ROS). Plants are adequately protected by the presence of multiple antioxidative enzymes in the cytosol and also in the different cell organelles such as chloroplasts, mitochondria, and peroxisomes. Traditionally, ROS were considered to be only a toxic byproduct of aerobic metabolism. However, recently it has become apparent that plants actively produce these molecules which may control many different physiological processes such as abiotic and biotic stress response, pathogen defense and systemic signaling. The search results using the Citrus Genome Program in Brazil (CitEST) for oxidative stress and the antioxidant enzyme system in Citrus Sinensis variety 'Pera IAC' indicated that the multiple ROS-scavenging enzymes were expressed throughout all citrus tissues. The analyses demonstrated the ubiquitous expression of metallothioneins, probably indicating a constitutive expression pattern. Oxalate oxidase has been identified as the most abundant expressed gene in developing fruits, which suggests a specific function in the ripening of citrus fruit. Moreover, infected leaves with Xylella fastidiosa and Leprosis citri showed a massive change in their ROS gene expression profile which may indicate that the suppression of ROS detoxifying mechanisms may be involved in the induction of the diseases.
\end{abstract}

Key words: citrus, genome, EST, reactive oxygen species, oxidative stress enzyme.

Received: September 4, 2006; Accepted: April 2, 2007.

\section{Introduction}

The appearance of oxygen in the atmosphere enabled respiratory metabolism and efficient energy generation systems which use molecular oxygen $\left(\mathrm{O}_{2}\right)$ as final electron acceptor, which led to the formation of reactive oxygen species (ROS) in cells (Temple et al., 2005). Although, atmospheric oxygen is relatively non-reactive, it can give rise to reactive oxygen intermediates which include superoxide $\left(\mathrm{O}_{2}{ }^{\circ}\right)$, hydrogen peroxide $\left(\mathrm{H}_{2} \mathrm{O}_{2}\right)$, hydroxyl radical $\left({ }^{\circ} \mathrm{OH}\right)$, and singlet oxygen $\left({ }^{1} \mathrm{O}_{2}\right)$ (Scandalios, 2005).

In plants, ROS are produced continuously as byproduct of various physiological metabolic pathways, such as photosynthesis, photorespiration and $\mathrm{CO}_{2}$ assimilation. Furthermore, ROS production is increased by several environmental factors of stress, such as exposition to high levels

Send correspondence to Dagmar Ruth Stach-Machado. Departamento de Microbiologia e Imunologia, Universidade Estadual de Campinas, Caixa Postal 6109 13081-862 Campinas, SP, Brazil. E-mail:dmachado@unicamp.br. of light, drought, heavy metals, salt concentrations, temperature extremes, air pollution, UV radiation, herbicides and pathogen attacks. Whether ROS will act as damaging, protective or signaling factors depends on the delicate equilibrium between ROS production and scavenging at the proper site and time (Gratão et al., 2005).

The enzymatic ROS scavenging mechanisms in plants include: superoxide dismutase (SOD), the waterwater cycle (WWC), the ascorbate-glutathione cycle (AGC), the glutathione peroxidase cycle (GPXC), and catalase (CAT) (Apel and Hirt, 2004) (Figure 1).

SOD catalyzes the dismutation of superoxide radical in a broad range of organisms, including plants. The dismutation of superoxide into hydrogen peroxide and oxygen constitute the first line of cellular defense to prevent undesirable biological oxidation by oxygen radical generated during cellular metabolism. Based on the metal co-factor used by the enzyme, SODs are classified into three groups: iron SOD (FeSOD), manganese SOD 
(MnSOD), and copper-zinc SOD (Cu/ZnSOD) (Alscher $e t$ al., 2002).

In plant cells, one of the most important detoxification systems is the WWC which operates together with SOD as a mechanism of hydrogen peroxide scavenging in intact chloroplasts (Edreva, 2005; Asada, 2006). The most important function of this cycle is a rapid, immediate scavenging of $\mathrm{O}_{2}{ }^{-}$and $\mathrm{H}_{2} \mathrm{O}_{2}$ at the site of its generation prior to their interaction with the target molecules. Ascorbate peroxidase (APX) uses two molecules of ascorbate to reduce $\mathrm{H}_{2} \mathrm{O}_{2}$ to water, with the concomitant generation of two molecules of monodehydroascorbate (MDHA). MDHA is a radical with a short lifetime, which is reduced directly to ascorbate within the chloroplast at the thylakoid membrane (Figure $1 \mathrm{~A}$ ).

Hydrogen peroxide can also be converted into water by the AGC which involves successive oxidations and reductions of ascorbate, glutathione and NADPH by enzymes: APX, glutathione reductase (GR); dehydroascorbate reductase (DHAR); and monodehydroascorbate reductase (MDHAR) (Figure $1 \mathrm{~B}$ ). The reducing agent in the first reaction catalyzed by APX is ascorbate, which is oxidized into MDHA that can be regenerated by MDHAR using $\mathrm{NAD}(\mathrm{P}) \mathrm{H}$ as a reducing equivalent. MDHA can spontaneously dismutase into dehydroascorbate (DHA). The ascorbate regeneration is mediated by DHAR driven by oxidation of glutathione (GSH) to glutathione disulphide (GSSG). Finally, the cycle closes with GR converting GSSG back into GSH using $\mathrm{NAD}(\mathrm{P}) \mathrm{H}$ as a reducing agent.

The GPXC (Figure 1 C) also detoxifies hydrogen peroxide to water but uses glutathione directly as a reducing agent. The oxidized GSSG is converted into GSH by GR using NAD $(\mathrm{P}) \mathrm{H}$.

Catalase (CAT) is responsible to dismutation of hydrogen peroxide into oxygen and water in the peroxisomes, protecting the cell from the deleterious effects of hydrogen peroxide accumulation (Figure $1 \mathrm{D}$ ). Multiple isoenzymes of CAT have been studied in higher plants, and in maize, three main CAT isoforms have been characterized (Scandalios, 2005).

Besides all enzymatic scavenging-pathways, plant cells have numerous non-enzymatic antioxidant molecules, which are also involved in protection against oxidative stress and damage caused by ROS. The main non-enzymatic antioxidant molecules are ascorbate and glutathione, which are integrated in the cycles above, flavonoids, alkaloids, phenolic compounds, $\alpha$-tocopherol and carotenoids, which help in scavenging of ROS (Foyer and Noctor, 2005). Furthermore, the metal chelators, such as metallothioneins (MT) and ferritins (FT), due to their metalbinding activity play an important role in metal metabolism and detoxification (Briat et al., 1999).

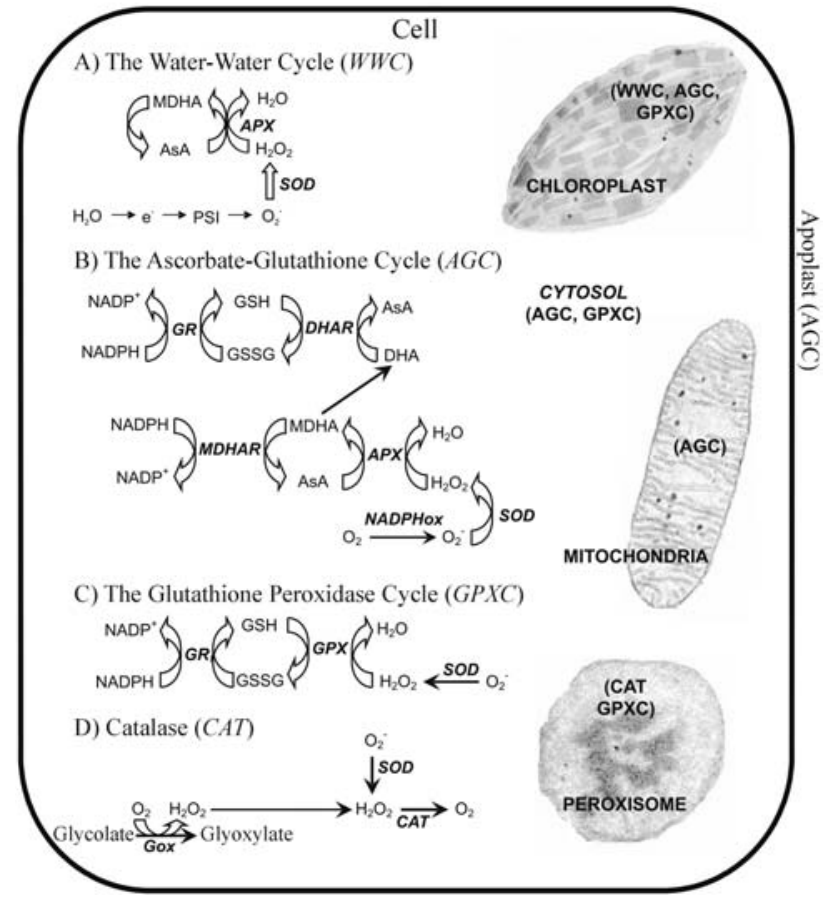

Figure 1 - Localization of reactive oxygen species (ROS) scavenging pathways in plant cells. (A) The water-water cycle (WWC); (B) The ascorbate-glutathione cycle (AGC); (C) The glutathione peroxidase cycle (GPXC); (D) Catalase (CAT). APX, ascorbate peroxidase; AsA, ascorbate; CAT, catalase; DHA, dehydroascorbate; DHAR, dehydroascorbate reductase; Gox, glycolate oxidase; GPX, glutathione peroxidase; GR, glutathione reductase; GSH, glutathione; GSSG, oxidized glutathione; MDHA, monodehydroascorbate; MDHAR, monodehydroascorbate reductase; NADPHox, NADPH oxidase; PSI, photosystem I and SOD, superoxide dismutase.

In spite of the presence of an efficient antioxidant system, oxidative damage still occur in plant cells either due to uncontrolled production or inefficient scavenging of ROS. Plant tissue senescence and fruit ripening is generally accompanied by higher production of ROS and gradual loss in the ability of scavenging enzymes to neutralize the free radicals (Palma et al., 2006).

In this work, the expression of oxidative and antioxidative stress enzymes in Citrus sinensis variety 'Pera IAC' was analyzed. For this purpose, a battery of ROS scavenging enzymes and non-enzymatic antioxidants were searched in young and adult leaves, bark and flower, fruit in different maturation stages, and leaves infected with Xylella fastidiosa and Leprosis citri using the EST sequencing project.

\section{Material and Methods}

cDNA libraries from different citrus tissues such as leaf, bark, fruit and flower were constructed by reverse transcription using mRNA as a model. Traditionally, one problem of Expressed Sequence Tags (EST) library construction is the overabundance of short and truncated EST 
fragments due to incomplete reverse-transcription reaction and the ligation bias toward small inserts. This can result in a disproportionately high number of false undiscovered 'novel' sequences due to insufficient coding sequence to establish identity accurately by homology to existing coding sequences. Then, to improve the proportion of fulllength and large EST fragments and minimize the overlap of very short inserts in the libraries, the amplified cDNA were size-selected and those with less than approximately 650 bp were discarded.

Considering the entire CitEST database, in this work only Citrus sinensis 'Pera IAC' ESTs were considered in the analysis of reads involved in the oxidative stress response, and these ESTs were divided into different groups according to standard CitEST reads nomenclature.

So, each read code refers to leaf $(\mathrm{C} 1)$, bark (C2), fruit (C3) and flower (C5), as well as, different conditions, such as non-infected tissue (100), tissue infected by $X$. fastidiosa, stage 1 (101), 30 days after infection by $X$. fastidiosa (102), infected by Citrus leprosis virus (401), young tissue (650), healthy plants growing in green house (003), development stage 1 (700), development stage 2 (701), development stage 3 (702), development stage 4 (703), development stage 5 (704), and development stage 6 (705) (Table 1).

Citrus EST database was mined by use of program GeneProject v.1. Sequences related to plant oxidative stress enzymatic and non-enzymatic responses were found by keyword search, and reads presenting a BLASTX match for annotation with an E-value lower than $10^{-15}$ were selected (Altschul et al., 1990). This E-value was chosen to ensure that the annotation was based only on genes with a high degree of similarity to citrus cDNA clones.

ESTs with identical or extremely similar putative annotations were counted and their frequency was normalized per thousand in relation to the total number of ESTs in each corresponding library. Normalized frequencies were used for expression pattern hierarchical clustering using Hierarchical Clustering Server in GEPAS online tools (Herrero et al., 2003, 2004), separating high and low expressed sequences in each analysis.

\section{Results and Discussion}

\section{Antioxidant system in Citrus EST database}

A complex enzymatic system is responsible for the control of the ROS, which are produced by many different processes in plants, and these enzymes can be divided into two groups. The first group is involved in the oxidative stress which produces ROS and comprises the enzymes such as glycolate oxidase (GOX), NADPH oxidase (NADPHox) and oxalate oxidase (OXO); whereas, the second one, the antioxidative stress system, is responsible for
Table 1 - EST libraries in Citrus sinensis variety 'Pera IAC' showing specific tissues, several treatments and number of reads.

\begin{tabular}{|c|c|c|c|c|}
\hline Library & Type & Tissue & Treatment & $\begin{array}{c}\text { Number of } \\
\text { reads }\end{array}$ \\
\hline CS $00 \mathrm{C} 1100$ & cDNA & Leaf & Non-infected & 7185 \\
\hline CS $00 \mathrm{C} 1650$ & cDNA & Leaf & Young tissue & 2865 \\
\hline CS 00 C2 003 & cDNA & Bark & $\begin{array}{l}\text { Plants growing in } \\
\text { green house }\end{array}$ & 5451 \\
\hline CS 00 C5 003 & cDNA & Flower & $\begin{array}{l}\text { Plants growing in } \\
\text { green house }\end{array}$ & 4330 \\
\hline CS 00 C3 700 & cDNA & Fruit & Stage $1(1.0 \mathrm{~cm})$ & 8454 \\
\hline CS 00 C3 701 & cDNA & Fruit & Stage $2(2.5 \mathrm{~cm})$ & 7052 \\
\hline CS 00 C3 702 & cDNA & Fruit & Stage $3(5.0 \mathrm{~cm})$ & 7909 \\
\hline CS 00 C3 703 & cDNA & Fruit & Stage $4(7.0 \mathrm{~cm})$ & 6387 \\
\hline CS 00 C3 704 & cDNA & Fruit & Stage $5(8.0 \mathrm{~cm})$ & 6242 \\
\hline CS 00 C3 705 & cDNA & Fruit & Stage $6(9.0 \mathrm{~cm})$ & 6712 \\
\hline CS 00 C1 101 & cDNA & Leaf & $\begin{array}{l}\text { Infected by Xylella } \\
\text { fastidiosa stage } 1\end{array}$ & 5899 \\
\hline CS $00 \mathrm{C} 1102$ & cDNA & Leaf & $\begin{array}{c}\text { Infected by } X \text {. } \\
\text { fastidiosa } a \text { after } 30 \\
\text { days }\end{array}$ & 7231 \\
\hline CS $00 \mathrm{C} 1401$ & cDNA & Leaf & $\begin{array}{l}\text { Infected by Citrus } \\
\text { leprosis stage } 1 .\end{array}$ & 945 \\
\hline
\end{tabular}

ROS scavenging which comprises the enzymes, such as SOD, APX, CAT, glutathione peroxidase (GPX), and $\alpha$-tochopherol.

The ESTs from Citrus Sinensis variety 'Pera IAC' related to the oxidative and antioxidative stress systems comprise 38 isoforms, which 4 were related to ROS production, while 14 isoforms were first described as direct ROS scavenging enzymes and 20 isoforms were related to indirect ROS scavenging system due to their participation in production of antioxidant products such as glutathione and ascorbate (Table 2).

Then, for each EST isoform, the total relative abundance was calculated considering the 13 different libraries (Table 1), the E-value from BLASTX server (Altschul et al., 1990), as well as the amino acid identity according to GenBank non-redundant database from National Center for Biotechnological Information (NCBI).

All EST clones were putatively annotated by similarity to coding sequences in the GenBank non-redundant database with approximately $42 \%$ of all reads sharing $80 \%$ or higher similarity with existing sequences. The same percentage was observed to reads that had similarity of between $60 \%-80 \%$ and, more than $15 \%$ shared less than $60 \%$ similarity to known coding sequences (Table 2).

The OXO from $A$. thaliana $\left(\right.$ E-value $\left.=7 \mathrm{e}^{-78}\right)$ had the highest relative abundance index $\left(83.5 \times 10^{-4}\right)$, followed by $\mathrm{Cu} / \mathrm{Zn}$ SOD isoform 1 from M. crystallinum $\left(12.0 \times 10^{-4}\right)$. The other three isoforms (catalase 1 - CAT1; Glycolate 
Table 2 - Overview of the oxidative and antioxidative stress systems in Citrus sinensis variety 'Pera IAC' showing their similarities with other organisms, relative abundance $\left(\times 10^{-4}\right)$ and amino acid identities.

\begin{tabular}{|c|c|c|c|c|c|}
\hline Enzyme & Organism & $\begin{array}{l}\text { Total number } \\
\text { of ESTs }\end{array}$ & $\begin{array}{c}\text { Relative } \\
\text { abundance }\left(\times 10^{-4}\right)\end{array}$ & E-value & $\begin{array}{l}\text { Amino acid } \\
\text { identity }\end{array}$ \\
\hline \multicolumn{6}{|l|}{ Production } \\
\hline GOX & S. oleracea & 4 & 1.85 & $e^{-179}$ & $318 / 368(86 \%)$ \\
\hline GOX2 & A. thaliana & 52 & 9.31 & 0.0 & $333 / 368(90 \%)$ \\
\hline NADPH Oxidase & N. tabacum & 16 & 5.20 & 0.0 & $576 / 720(80 \%)$ \\
\hline OXO & A. thaliana & 305 & 83.5 & $7 e^{-78}$ & $145 / 222(65 \%)$ \\
\hline \multicolumn{6}{|l|}{ Direct scavenging } \\
\hline APX1 & A. thaliana & 15 & 4.25 & $\mathrm{e}^{-122}$ & $205 / 249(82 \%)$ \\
\hline APX2 & G. $\max$ & 8 & 2.87 & $\mathrm{e}^{-124}$ & $212 / 248(85 \%)$ \\
\hline APX3 & A. thaliana & 19 & 3.85 & $e^{-165}$ & $293 / 369(79 \%)$ \\
\hline APX4 & L. esculentum & 3 & 1.92 & $\mathrm{e}^{-137}$ & $251 / 347(72 \%)$ \\
\hline CAT1 & G. hirsutum & 75 & 9.9 & 0 & 453 / $492(92 \%)$ \\
\hline CAT2 & A. thaliana & 37 & 6.27 & 0 & $406 / 493(82 \%)$ \\
\hline GPX & P. fluorescens & 5 & 8.0 & $2 \mathrm{e}^{-77}$ & $140 / 157(89 \%)$ \\
\hline GPX1 & P. sativum & 20 & 4.0 & $2 \mathrm{e}^{-90}$ & $174 / 246(70 \%)$ \\
\hline GPX2 & A. thaliana & 9 & 2.71 & $8 \mathrm{e}^{-72}$ & $126 / 162(77 \%)$ \\
\hline GPX3 & A. thaliana & 5 & 1.75 & $2 \mathrm{e}^{-67}$ & $120 / 169(71 \%)$ \\
\hline GPX4 & C. sinensis & 23 & 4.24 & $3 e^{-92}$ & $166 / 167(99 \%)$ \\
\hline $\mathrm{SOD} \mathrm{Cu/Zn} 1$ & M. crystallinum & 40 & 12.0 & $2 \mathrm{e}^{-75}$ & $127 / 152(83 \%)$ \\
\hline SOD Fe 2 & G. $\max$ & 21 & 4.90 & $\mathrm{e}^{-102}$ & $175 / 231(75 \%)$ \\
\hline SOD Mn & H. brasiliensis & 16 & 3.77 & $\mathrm{e}^{-106}$ & $186 / 231(80 \%)$ \\
\hline \multicolumn{6}{|l|}{ Indirect scavenging } \\
\hline FT & P. aeruginosa & 8 & 3.13 & $2 \mathrm{e}^{-96}$ & $173 / 213(81 \%)$ \\
\hline FT1 & S. tuberosum & 8 & 4.76 & $e^{-91}$ & $170 / 256(66 \%)$ \\
\hline FT3 & G. $\max$ & 15 & 3.30 & $\mathrm{e}^{-110}$ & $205 / 262(78 \%)$ \\
\hline GGCS & L. esculentum & 8 & 2.39 & 0 & $436 / 526(82 \%)$ \\
\hline GR1 & P. Sativum & 8 & 2.26 & 0 & $405 / 480(84 \%)$ \\
\hline GR2 & N. tabacum & 3 & 3.55 & $4 e^{-70}$ & 69 / $82(84 \%)$ \\
\hline GS & B. juncea & 7 & 2.64 & $\mathrm{e}^{-106}$ & $183 / 237(77 \%)$ \\
\hline GSTF & H. muticus & 6 & 2.70 & $2 \mathrm{e}^{-50}$ & $94 / 212(44 \%)$ \\
\hline GSTF3 & A. thaliana & 28 & 5.25 & $3 e^{-78}$ & $133 / 206(64 \%)$ \\
\hline GSTU6 & O. sativa & 24 & 3.56 & $1 \mathrm{e}^{-62}$ & $118 / 228(51 \%)$ \\
\hline GSTX2 & N. tabacum & 25 & 5.9 & $1 \mathrm{e}^{-61}$ & $117 / 222(52 \%)$ \\
\hline GSTX4 & N. tabacum & 7 & 1.89 & $7 e^{-98}$ & $166 / 221(75 \%)$ \\
\hline GSTX6 & G. Max & 20 & 4.13 & $1 e^{-51}$ & $99 / 215(46 \%)$ \\
\hline GSTXA & A. thaliana & 3 & 3.79 & $9 e^{-60}$ & $111 / 211(53 \%)$ \\
\hline HGGT & $V$. vinifera & 9 & 2.46 & $\mathrm{e}^{-134}$ & $245 / 364(67 \%)$ \\
\hline MDHAR1 & A. thaliana & 4 & 2.56 & $3 e^{-98}$ & $163 / 216(74 \%)$ \\
\hline MDHAR4 & C. sativus & 33 & 5.91 & 0.0 & $358 / 434(82 \%)$ \\
\hline MT2 & A. chinensis & 60 & 7.83 & $4 e^{-28}$ & 54 / $79(68 \%)$ \\
\hline MT3 & C. papaya & 49 & 9.23 & $\mathrm{e}^{-23}$ & 46 / $66(69 \%)$ \\
\hline TPT1 & A. thaliana & 15 & 3.54 & $8 \mathrm{e}^{-43}$ & $64 / 136(47 \%)$ \\
\hline
\end{tabular}


oxidase 2 - GOX2 and Metallothionein 3 - MT3) had approximately $9.48 \times 10^{-4}$ to their relative abundance index. The remaining enzymes represent a mean value approximately of $3.6 \times 10^{-4}$.

\section{Expression profile of oxidative and antioxidative enzymes in leaf, bark and flower}

The production of ROS in plant cells is a normal and continuously occurring phenomenon and in leaf cells, there is an intricate balance between $\mathrm{H}_{2} \mathrm{O}_{2}$ and $\mathrm{O}_{2}{ }^{-}$production and the activities of the ROS-scavenging enzymes. In Arabidopsis thaliana, a network of at least 152 genes controls ROS metabolism (Mittler et al., 2004). The network is thought to regulate the rates of ROS production and ROS scavenging in the different cellular compartments and to modulate the steady-state level of ROS.

The ESTs from citrus leaves (Figure 2 Row 1) showed that all major enzymes involved in ROS-scavenging mechanisms were expressed, including SOD, CAT and the majority of AGC enzymes, like APX and GR. In healthy leaves, the chloroplastic antioxidative enzymes
FeSOD and $\mathrm{Cu} / \mathrm{ZnSOD}$ were found and the main peroxisomal enzyme catalase isoform 2 (CAT2) was overexpressed.

In addition to enzymatic detoxification of ROS, the control of the concentration of free metals is an important complementary way to prevent oxidative damage in plant cells. Healthy leaves, also overexpressed metallothionein isoform 2 (MT2), which are low-molecular weight and cysteine-rich proteins are thought to be involved in heavy metal storage, detoxification and homeostasis, due to extensively metal release inherent to their development process in plants (Cobbett and Goldsbrough, 2002). However, MTs are not only involved in maintaining homeostasis of essential metals and metal detoxification, but are also implicated in a range of physiological processes, including scavenging ROS, regulating cell growth, and proliferation.

In young leaves, bark and flower tissues (Figure 2 Row 2, 3 and 4, respectively) several of the well-documented oxidative and antioxidative stress enzymes were not identified in the present study. This is probably because ESTs are only a snapshot of gene expression in a particular

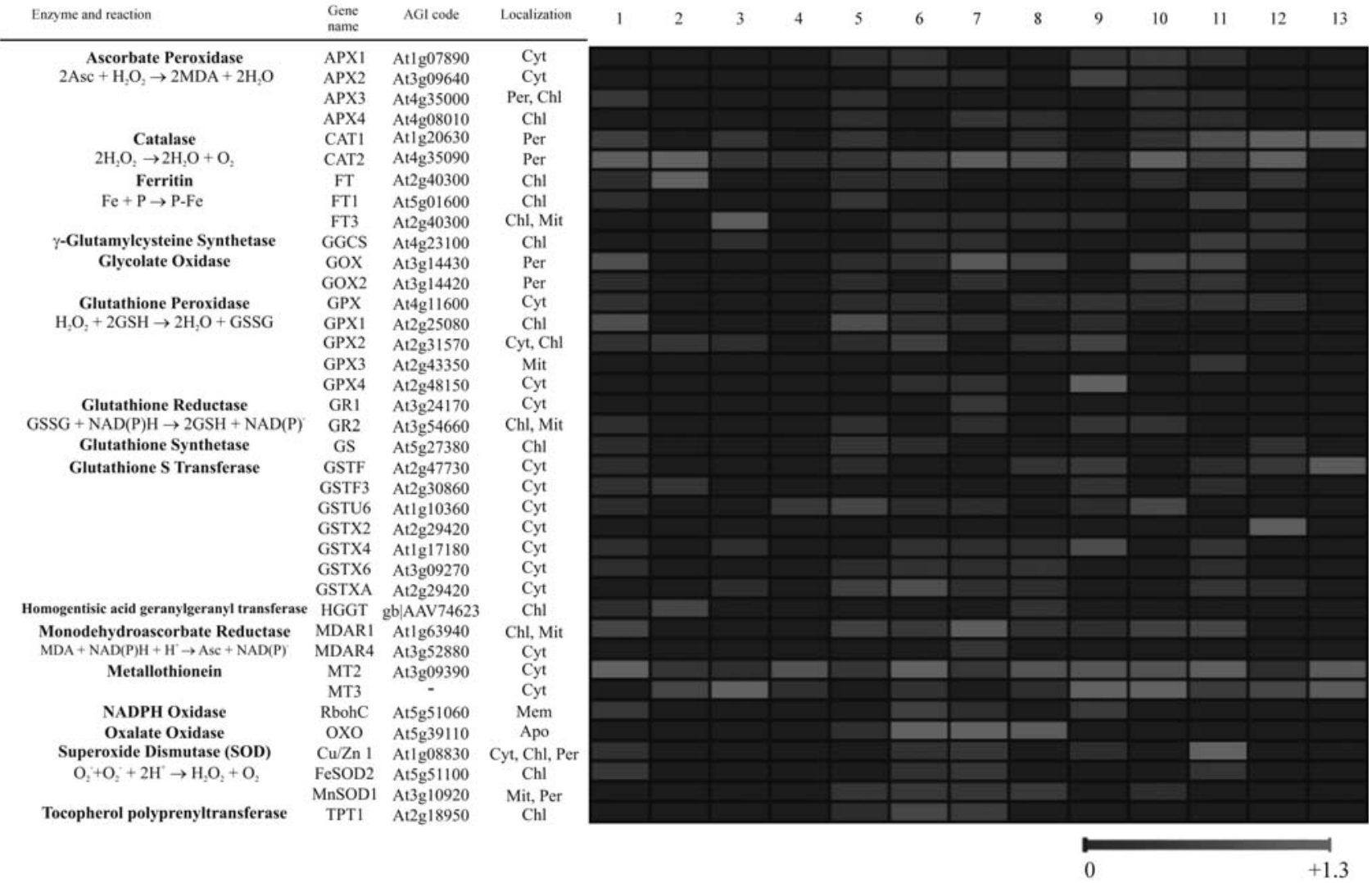

Figure 2 - Expression profile of enzymes and polypeptides of antioxidant system of Citrus sinensis variety 'Pera IAC' submitted to several treatments (1) Leaf cDNA from non-infected tissue; (2) Leaf cDNA from young tissue; (3) Bark cDNA of healthy plants growing in green house; (4) Flower cDNA of healthy plants growing in green house; (5) Fruit cDNA of development stage 1; (6) Fruit cDNA of development stage 2; (7) Fruit cDNA of development stage 3; (8) Fruit cDNA of development stage 4; (9) Fruit cDNA of development stage 5; (10) Fruit cDNA of development stage 6; (11) Leaf cDNA from tissue infected by Xylella fastidiosa stage 1; (12) Leaf cDNA with 30 days after infection by $X$. fastidiosa; and (13) Leaf cDNA from tissue infected by Citrus leprosis stage 1 . All data were multiplied by $10^{3}$ to GEPAS online tool analysis. 
tissue and stage of development, and these tissues may have minor photosynthetic activity when compared with adult leaf tissue.

Young leaves overexpressed CAT2 and the enzymes involved in cellular iron homeostasis like FT, MT2 and MT3 (Becana et al., 1998). However, all tissues expressed MT2 and MT3, which prevent the formation of the highly toxic hydroxyl radical via the metal-dependent HaberWeiss reaction (Fenton reaction) (Van Breusegem et al., 2001).

\section{Expression pattern of oxidative and antioxidative stress enzymes within growing citrus fruits}

Fruit development and ripening are complex processes involving major changes in fruit metabolism. Fruit development is a genetically regulated process, and it takes 6-8 months to reach maturity in citrus fruit. Orange fruit needs to be matured on the plant. If harvested prematurely, the fruit does not continue to ripen or sweeten, as there are no starch reserves in the fruit to be converted to sugar.

Fruit ripening has been described as an oxidative phenomenon, characterized by oxidative stress with chlorophyll and protein breakdown. Plant cells produce ROS, particularly superoxide and hydrogen peroxide, which have been implicated as a second messenger in many processes associated with plant growth and development. In general, fruits are divided into two large groups, climacteric and non-climacteric, based upon the presence or absence of an autocatalytic ethylene burst during ripening. In climacteric fruits, such as tomato, apple and banana (Clendennen and May, 1997; Jimenez et al., 2002; Mondal et al., 2004), the burst of ethylene biosynthesis plays a crucial role in the control of the ripening process by regulating the transcriptions of a large number of genes. However, in non-climacteric fruits, such as strawberry and citrus, oxidative stress-related genes were upregulated in ripening (Aharoni and O'Connell, 2002).

The gene expression pattern of oxidative and antioxidative stress enzymes from CitEST libraries using fruits of different size are shown in Figure 2, Rows 5 to 10. All oxidative and antioxidative stress enzymes were present throughout the different fruit size stages. By comparing different fruit stages, it was possible to observe changes in the intensity profile of the expression pattern of enzymes isoforms during fruit development. The largest number of enzymes and their isoforms were found within orange fruits in stage 1 , with $1.0 \mathrm{~cm}$ of diameter, and the smallest number in fruits stage 6.

CAT represents one of the primary enzymatic defenses against oxidative stress induced by senescence (Zimmermann et al. 2006). Although this enzyme was expressed in all fruit stages, it was overexpressed in fruits stages 3 and 4. Furthermore, increases in catalase activity during ripening also have been reported in many fruits (Sala and Lafuente, 1999).

MT genes were the most highly expressed in citrus fruits and were overexpressed in fruits stages 5 and 6. MTs are thought to be involved in both heavy metal detoxification and cellular homeostasis of essential trace metals, such as zinc and cooper. Because of the nature of its metalbinding activity and induction by heavy metal ions, MT genes are strongly believed to play a role in metal ion metabolism and metal tolerance mechanisms.

The data available regarding the expression of MT genes from a variety of plant species indicate that each MT gene type exhibits characteristic temporal and tissue specific expression pattern (Chen et al., 2003). During fruit development, it has been reported that MT has an upregulated gene expression in climacteric as well as in non-climacteric fruits. Citrus and pineapple, non-climacteric fruits, express two MT genes that exhibit similar expression patterns across ripening (Moriguchi et al., 1998; Moyle et al., 2005). Both MT2 and MT3 were detected in developing fruit, but were differentially expressed. MT2 was expressed during the entire ripening process of citrus fruit, whereas MT3 had an expression peak in the later stages of fruit development. The expression of MT is confined to specific stages of fruit development. This differential expression of MT genes strongly suggests that each MT isoform may have specialized functions in different tissues. Some of the functions proposed for plant MTs include a role during development, in senescence and in protection against oxidative stress.

The analysis of expression pattern from developing citrus fruit showed that OXO or germin-like protein (GLP) is the most abundant gene product. OXO is one of the enzymes that produces $\mathrm{H}_{2} \mathrm{O}_{2}$ in plants. OXO is a glycosylated protein localized in the apoplast and is a known marker protein in the germination of wheat seeds (Custers et al., 2004). Various studies have revealed that GLP may play an important role in plant development and shows responsiveness to biotic and abiotic stresses. These enzymes are highly expressed during germination of wheat and barley and in response of mature leaves to pathogen (Lane, 2002). However the exact biological significance of the $\mathrm{H}_{2} \mathrm{O}_{2}$ production by $\mathrm{OXO}$ in plants remains unknown.

\section{Expression pattern of oxidative stress enzymes during infection with Xylella fastidiosa and Leprosis citri}

Plants have developed a complex defense system to combat invading pathogens, which includes pre-formed and induced components. Plants respond to pathogens by transient increase in the production of ROS and ion fluxes (Dat et al., 2000). This is the so-called "oxidative burst" a 
hallmark of successful recognition of plant pathogens (Lamb and Dixon, 1997; De Gara et al., 2003).

Oxidative burst means a massive, rapid and transient activation of oxidative metabolism with the generation of ROS such as superoxide anions and hydrogen peroxide, after exposure to certain abiotic and biotic stress factors (Torres and Dangl, 2005; Torres et al., 2006). This oxidative burst triggered by an imbalance in the production and metabolism of ROS was described by Doke (1983) in plant cells exposed to pathogens. It has been shown that ROS have a direct antimicrobial effect on the pathogen. They are involved in the cross-linking of cell walls around the site of infection and also, activate both local programmed cell death and systemic increase in stress-induced pathogen resistance (Mahalingam and Fedoroff, 2003; Van Breusegem and Dat, 2006).

In incompatible interactions the oxidative burst is a biphasic response that comprises a primary peak $1-2 \mathrm{~h}$ after infection, followed by a secondary peak of greater magnitude after 3-6 h. However in compatible interactions, the peak is monophasic (Melillo et al., 2006).

$X$. fastidiosa is a gram negative bacterium and lives exclusively within xylem vessels (Bové and Garnier, 2002). The bacterium multiplies and spreads within the xylem developing a systemic disease by plugging the xylem vessels with pectins, tyloses, and gums produced by the plant in response to bacteria, and causing the chlorosis variegated disease in citrus. Citrus leprosis (CiLV) is non-systemic virus disease that occurs on sweet orange (Rodrigues et al., 2003). The disease is characterized by localized lesions on leaves, twigs and fruits. The early damage on fruit consists of areas with chlorotic yellow spots, and late damage includes necrotic brown lesions which recall the socalled hypersensitive reaction (HR) (Levine et al., 1994).

The comparison of the gene expression profiles between healthy leaves (Figure 2 Row 1 ) and $X$. fastidiosa infected leaves stage 1 (Figure 2 Row 11) revealed that these two tissues have very similar expression profiles of oxidative enzymes with only slight differences. Infected leaves overexpressed $\mathrm{Cu} / \mathrm{Zn}$ SOD isoform, which probably enhances the protection of leaves against specific stresses (Foyer et al., 2001). Infected leaves expressed CAT1 and CAT2 at similar levels and higher levels of APX isoforms, while overexpressing the MT2 gene when compared with healthy leaves.

However, the ESTs profile from leaves with 30 days of infection by $X$. fastidiosa or CiLV showed a massive change in the gene expression of enzymatic and non-enzymatic antioxidative mechanisms (Figure 2 Row 12 and 13). Leaves infected with $X$. fastidios $a$ or CiLV had no expression of SOD, which suggests that chloroplasts from infected leaves are unable to remove the $\mathrm{O}_{2}{ }^{-}$radicals generated in the photosynthetic electron transport chain. The
Mehler-peroxidase cycle or WWC in chloroplast performs an essential protective function in preventing the accumulation of superoxide and hydrogen peroxide (Foyer and Noctor, 2000; Noctor, 2006).

Infected leaves overexpressed the $\mathrm{H}_{2} \mathrm{O}_{2}$ scavenging enzymes such as CAT. $X$. fastidiosa infected leaves overexpressed both isoforms CAT1 and CAT2 whereas CiLV infected leaves overexpressed CAT1 only, which has a major role in $\mathrm{H}_{2} \mathrm{O}_{2}$ scavenging during photorespiration by preventing hydrogen peroxide accumulation. In plants, CAT represents one of the primary enzymatic defenses against oxidative stress induced by senescence, chilling, dehydration, osmotic stress, wounding, paraquat, ozone and heavy metals which rapidly breaks down hydrogen peroxide (Singh and Tewari, 2003).

Infection with $X$. fastidios $a$ and CiLV induced overexpression of the glutathione S-transferase (GST) gene. GST has GPX activity, thereby protecting cells from oxidative injury by detoxifying organic peroxides produced in plants during processes such as photosynthesis and pathogen attack. Moreover, GST is upregulated in many plants in response to a range of stress conditions (Dean et al., 2005). $X$ fastidiosa infected leaves expressed MT1 and MT2, while CiLV infected leaves overexpressed both genes.

Our results from the comparison between infected and healthy leaves clearly demonstrated that cells from infected leaves will accumulate ROS while their scavenging capacities are decreased or even absent. The suppression of ROS detoxifying mechanisms can be involved in the induction of these diseases.

\section{References}

Aharoni A and O'Connell AP (2002) Gene expression analysis of strawberry achene and receptacle maturation using DNA microarrays. J Exp Botany 53:2073-2087.

Alscher RG, Erturk N and Heath LS (2002) Role of superoxide dismutases (SODs) in controlling oxidative stress in plants. J Exp Botany 53:1331-1341.

Altschul SF, Gish W, Miller W, Myers EW and Lipman DJ (1990) Basic local alignment search tool. J Mol Biol 215:403-410.

Apel K and Hirt H (2004) Reactive oxygen species: Metabolism, oxidative stress, and signal transduction. Annu Rev Plant Biology 55:373-399.

Asada K (2006) Production and scavenging of reactive oxygen species in chloroplasts and their functions. Plant Physiol 141:391-396.

Becana M, Moran JF and Iturbe-Ormaetxe I (1998) Iron-dependent oxygen free radical generation in plants subjected to environmental stress: Toxicity and antioxidant protection. Plant Soil 201:137-147.

Bové JM and Garnier M (2002) Phloem and xylem-restricted plant pathogenic bacteria. Plant Sci 163:1083-1098.

Briat JF, Lobréaux S, Grignon N and Vansuyt G (1999) Regulation of plant ferritin synthesis: How and why. Cell Mol Life Sci 56:155-166. 
Chen HJ, Hou WC, Yang CY, Huang DJ, Liu JS and Lin YH (2003) Molecular cloning of two metallothionein-like protein genes with differential expression patterns from sweet potato (Ipomoea batatas) leaves. J Plant Physiol 160:547555.

Clendennen SK and May GD (1997) Differential gene expression in ripening banana fruit. Plant Physiol 155:463-469.

Cobbett C and Goldsbrough P (2002) Phytochelatins and metallothioneins: Roles in heavy metal detoxification and homeostasis. Annu Rev Plant Biol 53:159-182.

Custers JHHV, Harrison SJ, Sela-Buurlage MB, van Deventer E, Lageweg W, Howe PW, van der Meijs PJ, Ponstein AS, Simons BH, Melchers LS, et al. (2004) Isolation and characterization of a class of carbohydrate oxidases from higher plants, with a role in active defense. Plant J 39:147-160.

Dat J, Vandenabeele S, Vranová E, Van Montagu M, Inzé D and Van Bresegen F (2000) Dual action of the active oxygen species during plant stress responses. Cell Mol Life Sci 57:779-795.

De Gara L, de Pinto MC and Tommasi F (2003) The antioxidant systems vis-à-vis reactive oxygen species during plantpathogen interaction. Plant Physiol Biochem 41:863-870.

Dean JD, Goodwin PH and Hsiang T (2005) Induction of glutathione S-transferase genes of Nicotiana benthamiana following infection by Colletotrichum destructivum and $C$. orbiculare and involvement of one in resistance. J Exp Botany $56: 1525-1533$.

Doke N (1983) Involvement of superoxide anion generation in the hypersensitive response of potato-tuber tissues to infection with an incompatible race of Phytophthora infestans and to the hyphal wall components. Physiol Plant Pathol 23:345-357.

Edreva A (2005) Generation and scavenging of reactive oxygen species in chloroplasts: A submolecular approach. Agric Ecosyst Environ 106:119-133.

Foyer CH and Noctor G (2000) Oxygen processing in photosynthesis: Regulation and signaling. New Phytol 146:359-388.

Foyer CH and Noctor G (2005) Oxidant and antioxidant signaling in plants: A re-evaluation of the concept of oxidative stress in a physiological context. Plant Cell Environ 28:10561071.

Foyer CH, Theodoulou FL and Delrot S (2001) The functions of inter- and intracellular glutathione transport systems in plants. Trends Plant Sci 6:486-492.

Gratão PL, Polle A, Lea PJ and Azevedo RA (2005). Making the life of heavy metal-stressed plants a little easier. Funct Plant Biol 32:481-494.

Herrero J, Al-Shahrour F, Diaz-Uriarte R, Mateos A, Vaquerizas JM, Santoyo J and Dopazo J (2003) GEPAS: A web-based resource for microarray gene expression data analysis. Nucleic Acids Res 31:3461-3467.

Herrero J, Vaquerizas JM, Al-Shahrour F, Conde L, Mateos A, Diaz-Uriarte JSR and Dopazo J (2004) New challenges in gene expression data analysis and the extended GEPAS. Nucleic Acids Res 32:W485-W491.

Jimenez A, Creissen G, Kular B, Firmin J, Robinson S, Verhoeyen $\mathrm{M}$ and Mullineaux P (2002) Changes in oxidative processes and components of the antioxidant system during tomato fruit ripening. Planta 214:751-758.
Lamb C and Dixon RA (1997) The oxidative burst in plant disease resistance. Annu Rev Plant Physiol Plant Mol Biol 48:251275.

Lane BG (2002) Oxalate, germins, and higher-plant pathogens. IUBMB Life 53:67-75.

Levine A, Tenhaken R, Dixon R and Lamb C (1994) $\mathrm{H}_{2} \mathrm{O}_{2}$ from the oxidative burst orchestrates the plant hypersensitive disease resistance response. Cell 79:583-593.

Mahalingam R and Fedoroff N (2003) Stress response, cell death and signaling: The many faces of reactive oxygen species. Physiol Plantarum 119:56-68.

Melillo MT, Leonetti P, Bongiovanni M, Castagnone-Sereno P and Bleve-Zacheo T (2006) Modulation of reactive oxygen species activities and $\mathrm{H}_{2} \mathrm{O}_{2}$ accumulation during compatible and incompatible tomato-root-knot nematode interactions. New Phytol 170:501-512.

Mittler R, Vanderauwera S, Gollery, M and Van Breusegem F (2004) Reactive oxygen gene network of plants. Trends Plant Sci 9:490-498.

Mondal K, Sharma NS, Malhotra SP, Dhawan K and Singh R (2004) Antioxidant systems in ripening tomato fruits. Biol Plant 48:49-53.

Moriguchi T, Kita M, Hisada S, Endo-Inagaki T and Omura M (1998) Characterization of gene repertoires at mature stage of citrus fruits through random sequencing and analysis of redundant metallothionein-like genes expressed during fruit development. Gene 211:211-227.

Moyle R, Fairbairn DJ, Ripi J, Crowe M and Botella JR (2005) Developing pineapple fruit has a small transcriptome dominated by metallothionein. J Exp Botany 56:101-112.

Noctor G (2006) Metabolic signalling in defense and stress: The central roles of soluble redox couples. Plant Cell Environ 29:409-425.

Palma JM, Jiménez A, Sandalio LM, Corpas FJ, Lundqvist M, Gómez M, Sevilla F and Del Rio LA (2006) Antioxidative enzymes from chloroplasts, mitochondria, and peroxisomes during leaf senescence of nodulated pea plants. J Exp Botany $57: 1747-1758$.

Rodrigues JC, Kitajima EW, Childers CC and Chagas CM (2003) Citrus leprosis virus vectored by Brevipalpus phoenics (Acari, Tenuipalpidae) on citrus in Brazil. Exp Appl Acarol 30:161-179.

Sala, JM and Lafuente MT (1999) Catalase in the heat-induced chilling tolerance of cold-stored hybrid fortune mandarin fruits. J Agric Food Chem 47:2410-2414.

Scandalios JG (2005) Oxidative stress: Molecular perception and transduction of signals triggering antioxidant gene defenses Braz J Med Biol Res 38:995-1014.

Singh PK and Tewari RK (2003) Cadmium toxicity induced changes in plant water relations and oxidative metabolism of Brassica juncea L. plants. J Environ Biol 24:107-112.

Temple MD, Perrone GG and Dawes IW (2005) Complex cellular responses to reactive oxygen species. Trends Cell Biol 15:319-326.

Torres MA and Dangl JL (2005) Functions of the respiratory burst oxidase in biotic interactions, abiotic stress and development. Curr Opin Plant Biol 8:397-403. 
Torres MA, Jones JDG and Dangl JL (2006) Reactive oxygen species signaling in response to pathogens. Plant Physiol 141:373-378

Van Breusegem F, Vranová E, Dat JF and Inzé D (2001) The role of active oxygen species in plant signal transduction. Plant Sci 161:405-414.

Van Breusegem F and Dat JF (2006) Reactive oxygen species in plant cell death. Plant Physiol 141:384-390.

Zimmermann P, Heinlein C, Orendi G and Zentgraf U (2006) Senescence-specific regulation of catalases in
Arabidopsis thalianana (L.) Heynh. Plant Cell Environ 29:1049-1060

\section{Internet Resources}

CitEST GeneProject v.1.0, http://biotecnologia.centrodecitricul tura.br.

GEPAS, Gene Expression Pattern Analysis Suite v. 1.1, http:// gepas.bioinfo.cnio.es/cgi-bin/cluster.

Associate Editor: Reinaldo Montrazi Barata 